\title{
MEKANISME GOVERNANCE DAN PENGUNGKAPAN SUSTAINABLE FINANCE: UNTUK MELIHAT TINGKAT KESIAPAN PENERAPAN SUSTAINABLE FINANCE PADA PERUSAHAAN JASA KEUANGAN TERDAFTAR DI BEI
}

\author{
Salis Musta Ani dan Hotman Fredy \\ Universitas Pancasila \\ Email: salismusta@yahoo.co.id dan Email: hotmantugas@gmail.com
}

\begin{abstract}
This research is motivated by the lack of literature on the disclosure of sustainable finance and the need on preparing for the financial services industry in Indonesia to start implementing sustainable finance. In addition, the background of this research is the absence of standard setting of sustainable finance reporting standards, whereas the implementation of sustainable finance reporting is planned by OJK in 2016. This research is examination of influence of governance mechanism towards sustainable finance. Data is traced from financial services companies listed on the BEI. The research method used is multiple linear regression. The result proves that size of both company and the directors affect the disclosure of sustainable finance. This study also illustrates that the average of companies in Indonesia nowadays, when using measurement items based on International Finance Corporation (IFC), report components in sustainable finance is 0.35 on average. OJK needs to pay attention to this to provide more intensive guidelines for implementation and reporting of sustainable finance.
\end{abstract}

Keywords: Sustainable finance, corporate governance, mekanisme governance, green banking

\begin{abstract}
Abstrak: Penelitian ini dilatarbelakangi oleh minimnya literatur tentang pengungkapan sustainable finance dan perlunya persiapan dari industri jasa keuangan di Indonesia untuk mulai menerapkan sustainable finance. Selain itu, juga dilatarbelakangi oleh ketiadaan penetapan standar acuan pelaporan sustainable finance, padahal pelaksanaan pelaporan sustainable finance direncanakan oleh OJK pada tahun 2016. Penelitian ini merupakan pengujian pengaruh mekanisme governance terhadap sustainable finance. Data ditelusuri dari perusahaan jasa keuangan yang terdaftar di BEI. Metode penelitian yang digunakan adalah regresi linear berganda. Hasil penelitian membuktikan bahwa ukuran direksi dan size terbukti memengaruhi pengungkapan sustainable finance. Dalam penelitian ini juga diperoleh gambaran bahwa rata-rata perusahaan di Indonesia saat ini, jika menggunakan item pengukuran berdasarkan International Finance Corporation (IFC) melaporkan komponen dalam sustainable finance rata-rata sebesar 0,35. Hal ini perlu menjadi perhatian bagi pihak OJK untuk memberikan arahan yang lebih intensif mengenai pelaksanaan dan pelaporan sustainable finance.
\end{abstract}

Kata kunci: Sustainable finance, corporate governance, mekanisme governance, green banking 


\section{PENDAHULUAN}

Isu global tentang Corporate Social Responsibility (CSR) agaknya saat ini telah berkembang luas. Banyak perusahaan yang terdaftar di BEI telah melakukan aktivitas CSR dan melaporkannya, baik dalam annual report maupun dalam bentuk sustainability report. Isu global yang mengemuka telah membawa CSR ini dalam scope yang lebih luas. Agenda perusahaan bukan hanya melakukan aktivitas CSR semata, namun juga pencapaian atas aktivitas tersebut secara berkelanjutan. Perusahaan dalam lingkup global berlomba untuk menerapkan pembangunan berkelanjutan. Sebagai bentuk dari tuntutan transparansi publik, perusahaan memberikan pelaporan dalam bentuk annual report maupun pelaporan berkelanjutan atau sustainability report dalam dekade terakhir ini. Di Indonesia, ajang penghargaan untuk perusahaan yang melaporkan aktivitas CSR-nya juga digelar setiap tahun agar menjadi pendorong perusahaan untuk menyampaikan pelaporan CSR-nya. Sejalan dengan itu, berbagai standar pelaporan CSR juga dirumuskan berbagai pihak, salah satu standar pelaporan yang banyak digunakan sebagai panduan dalam penyusunan annual report maupun sustainabiliy report di Indonesia adalah GRI (Global Reporting Initiative).

Dalam dunia perbankan dan lembaga keuangan lain, muncul agenda baru, yaitu sustainable finance yang roadmap-nya telah diluncurkan oleh Otoritas Jasa Keuangan (OJK) bersama Kementerian Lingkungan Hidup dan Kehutanan (KLH) Republik Indonesia pada tanggal 5 Desember 2014 lalu (www.antaranews.com). Roadmap sustainable finance ini diluncurkan dengan harapan dapat menjadi instrumen pengungkit dalam memecahkan permasalahan lingkungan dan juga meningkatkan daya saing perusahaan jasa keuangan di Indonesia. Sustainable finance (keuangan berkelanjutan) ini merupakan dukungan menyeluruh dari industri jasa keuangan untuk pertumbuhan berkelanjutan yang dihasilkan dari keselarasan antara kepentingan ekonomi, sosial, dan lingkungan hidup (OJK, 2014).

Kajian mengenai sustainable finance ini masih minim karena relatif baru di Indonesia. Dalam scope internasional, beberapa peneliti telah melakukan pengujian dan pengamatan tentang sustainable finance ini. Penelitian Qingrong et al. (2013) memeroleh hasil bahwa 11 dari 12 perusahaan financial di China mengungkapkan sustainable finance secara terbuka, baik dalam annual report, annual sustainable development report, maupun annual social responsibility report. Selain itu, disebutkan pula bahwa bank di Beijing memberikan laporan dalam bentuk Annual Report on Environment and Social Performance kepada World Bank Group's International Financial Corporation (IFC).

Karena masih minimnya penelitian jenis ini dan dengan latar belakang bahwa OJK telah menetapkan 2015--2019 sebagai periode pertama pencapaian sustainable finance (jangka pendek), maka penelitian ini dilakukan untuk melihat kesiapan dunia perbankan dan industri jasa keuangan lain dalam menerapkan sustainable finance. Penelitian ini akan melihat pengaruh mekanisme corporate governance terhadap pengungkapan sustainable finance.

\section{KAJIAN TEORI}

Corporate Governance. Meskipun munculnya isu corporate governance (CG) telah lama didengungkan, hingga kini pelaksanaan good corporate governance (GCG) masih terus 
digalakkan oleh pemerintah. Penerapan GCG di perusahaan-perusahaan dan instansi pemerintah sudah semakin baik dan partisipan semakin meningkat.

Corporate governance merupakan prinsip-prinsip tentang pengaturan bagaimana manajemen bertindak secara pantas dalam menjalankan usahanya (Daniri, 2005). Menurut Komite Nasional Kebijakan Governance (KNKG), asas GCG terdiri dari: transparency, accountability, responsibility, independency, serta fairness (KNKG, 2006). Agar pelaksanaan good corporate governance dapat dipastikan telah terlaksana, diperlukan mekanisme governance. Keberadaan mekanisme governance ini dapat menjamin dan mengawasi pelaksanaan sistem governance tersebut (Syahroza, 2005).

Mekanisme governance dikelompokkan dalam dua bagian, yaitu mekanisme governance internal dan mekanisme governance eksternal. Menurut Syahroza (2005), mekanisme governance eksternal terdiri dari perangkat governance yang ada di dalam perusahaan, yaitu pemegang saham, RUPS, Dewan Komisaris, Dewan Direksi, serta pihak manajemen, termasuk internal auditor dan unit accounting. Sedangkan mekanisme governance eksternal terdiri dari private (stakeholder, reputational agent), dan regulatory.

Pelaporan sebagai Bentuk Transparansi Publik. Untuk dapat menjalankan good corporate governance, keempat asas governance di atas harus dipenuhi atau dijalankan. Salah satu asas yang harus dipenuhi adalah asas transparansi terhadap publik. Salah satu perwujudan dari asas transparansi ini adalah dengan melakukan pelaporan atas kinerja yang telah dicapai. Perusahaan harus memberikan informasi seluas-luasnya kepada publik tentang hal-hal yang telah dilakukan/ terjadi dan pencapaian hasilnya. Keterbukaan informasi bagi publik harus diupayakan melalui media yang tersedia, baik melalui annual report, maupun bentuk report khusus lain, serta website. Dalam prinsip transparansi, penyediaan informasi harus dilakukan secara tepat waktu, memadai, akurat, serta dapat diperbandingkan, dan mudah diakses oleh stakeholder sesuai dengan haknya (Daniri, 2005).

Agenda Sustainable Finance (Keuangan Berkelanjutan) dalam Industri Jasa Keuangan. Sustainable Finance menjadi trend global yang merupakan sebuah paradigma baru dalam dunia perbankan dan lembaga keuangan lain yang mendukung terlaksananya pembangunan berkelanjutan. Pembangunan berkelanjutan merupakan usaha pembangunan yang didasari tiga aspek orientasi, yaitu profit (keuntungan), people (hubungan sosial masyarakat), serta planet (perlindungan terhadap sumber daya alam dan lingkungan hidup (Hadad dan Maftuchah, 2015: 90). Istilah tersebut sering dikenal dengan triple bottom line. Menurut OJK (2014: 16), sustainable finance memiliki lima dimensi, yaitu pencapaian keunggulan industri, sosial, dan ekonomi dalam rangka mengurangi ancaman pemanasan global serta pencegahan terhadap permasalahan lingkungan hidup dan sosial lainnya; pergeseran target menuju ekonomi rendah karbon yang kompetitif; promosi investasi ramah lingkungan hidup di berbagai sektor usaha/ekonomi, dan pemberian dukungan pada pelaksanaan prinsip-prinsip pembangunan Indonesia 4P (pro-growth, projobs, pro-poor, dan pro-environment).

Dalam paradigma ini, industri jasa keuangan dapat memberikan dukungan terhadap program-program pembiayaan dan investasi yang berkelanjutan, seperti proyek biogas, micro hydro, pembangkit listrik tenaga air, tenaga surya, tenaga angin, pertanian organik, dan lain sebagainya.

Munculnya sustainable finance mendapat respon yang cukup luas, yaitu dari berbagai organisasi dunia yang menyuarakan keberlanjutan, termasuk inisiator standar. Di 
Indonesia, Otoritas Jasa Keuangan telah meluncurkan roadmap untuk memberikan pedoman rencana kerja program keuangan berkelanjutan (sustainable finance). Roadmap ini dijabarkan dalam dua periode pencapaian, jangka menengah (2015-2019) dan jangka panjang (2015-2024). Sustainable finance terdiri dari empat prinsip, yaitu (1) pengelolaan risiko, (2) prinsip pengembangan sektor ekonomi prioritas berkelanjutan, (3) prinsip tata kelola lingkungan hidup dan sosial serta pelaporan, (4) prinsip peningkatan kapasitas dan kemitraan kolaboratif. Dalam sustainable finance ini juga terdapat insentif, berupa insentif prudensial, antara lain ATMR (aktiva tetap mitigasi risiko) dengan memperhatikan mekanisme mitigasi risiko pada tahun 2015-2016 dan pada tahun 2016-2018 akan mendorong pemerintah untuk memberikan insentif fiskal, seperti tax holiday dan feed-in-tariff.

Beberapa istilah yang muncul sebagai wujud konsistensi dalam penerapan sustainable finance ini, yaitu Sustainable Banking atau Green Banking dalam dunia perbankan, Sustainable Capital Market, dan Green Bond dalam industri pasar modal, serta Green Insurance dalam Industri Keuangan Nonbank. Pada tanggal 23 November 2015 telah dilakukan penandatanganan green banking pilot project oleh beberapa perusahaan perbankan, yaitu PT Bank Arta Graha Internasional, Tbk., PT Bank Central Asia (BCA), Tbk., PT Bank Negara Indonesia (BNI), Tbk., dan PT Bank Rakyat Indonesia (BRI), Tbk., PT Bank BRI Syariah, PT Bank Mandiri, PT Bank Muamalat Indonesia, dan PT BPD Jabar dan Banten, Tbk. (http://finansial.bisnis.com/).

Standar Pelaporan Sustainable Finance. Munculnya sustainable finance ini kemudian disambut oleh para inisiator standar yang segera merumuskan dan meluncurkan pedoman bagi pelaporan sustainable finance. Standar pelaporan yang umum bagi semua industri yang selama ini dikenal adalah standar pelaporan dari: Global Reporting Initiative (GRI), United Nation Global Compact (UN Global- Compact 2000), Organisation for Economic Co-Operation and Development (OECD) Guidelines for Multinationals, Extractive Industry and Transparency Initiative (EITI), Sustainability Reporting Initiative (SRI). Sedangkan inisiatif standar pelaporan yang dapat digunakan untuk industri keuangan dan perbankan, yaitu International Finance Corporation - IFC Safeguard Policies, World Bank dan Pedoman Khusus International Finance Corporation - IFC, The Equator Principles - TEP (Project Finance), dan Principles for Responsible Investment (UN-PRI).

Karena belum terdapat pelaporan yang dijadikan acuan bagi industri jasa keuangan dan perbankan di Indonesia dalam sustainable finance ini, maka dalam penelitian ini item indeks sustainable finance mengacu pada IFC. IFC telah menerbitkan Performance Standards on Social and Environmental Sustainability (2006) sebagai pedoman standar kinerja keberlanjutan. Pedoman standar tersebut terdiri dari delapan standar kinerja yang disebutkan dalam Hadad dan Maftuchah (2015: 283) meliputi penilaian dan sistem manajemen lingkungan hidup dan sosial; ketenagakerjaan dan kondisi kerja; pencegahan dan penanggulangan pencemaran/polusi; kesehatan, keselamatan, dan keamanan masyarakat; akuisisi lahan dan pemindahan penduduk; konservasi keanekaragaman hayati dan pengelolaan sumber daya alam lestari; masyarakat adat; dan warisan budaya.

OJK mendorong sistem pelaporan sustainable finance melalui kebijakan pelaporan dalam tahap jangka pendek antara 2015-2019 ini. Dalam roadmap sustainable finance yang diluncurkan OJK, belum terlihat secara jelas standar pelaporan yang akan digunakan sebagai acuan industri keuangan dan perbankan di Indonesia, namun kebijakan pelaporan akan dilaksanakan pada tahun 2016 (OJK, 2014: 20). Agaknya OJK sedang mencari bentuk standar pelaporan yang sesuai atau jika melihat skema rencana kerja strategis 
dalam roadmap tertulis sustainability report (OJK, 2014: 21). Oleh karena itu, penelitian ini memberikan gambaran pelaporan jika akan digunakan standar yang berasal dari IFC. Penelitian Terdahulu. Penelitian dengan fokus kajian sustainable finance masih sangat minim. Kebanyakan penulisan tentang topik ini baru memberikan informasi dan pemikiran dasar, bukan riset berdasarkan pengamatan atau pengujian.

Qingrong, et al. (2013) melakukan perbandingan antara kinerja berkelanjutan bankbank di China dengan bank-bank dalam scope internasional. Banyak aspek yang diamati, yaitu strategy and policy framework, governance, procedures and tools, monitoring, reporting, and assurance, capacity building, dan sustainable financial products. Hasil penelitiannya menunjukkan bahwa kebanyakan bank yang diamati telah menerapkan kebijakan sustainability. Dalam pelaporan, lebih banyak bank yang merujuk pada standar internasional.

Oyegunle dan Weber (2015) menunjukkan bahwa China memiliki inisiatif dalam sustainable finance berupa kebijakan Green Credit Guideliness yang diterapkan pada tahun 2007, 2012, dan 2014. Demikian pula Ozcelik dan Ozturk (2014) menyebutkan bahwa perusahaan-perusahaan di Turkey telah memasukkan sustainability ke dalam strategi bisnis dan melakukan pelaporan sesuai Global Reporting Initiative (GRI). Mereka juga berpartisipasi dalam United Nations' G lobal Compact I nitiative.

Penelitian Gerster (2011) memberikan gambaran pelaksanaan sustainable financing di Switzerland. Selain itu, Gerster (2011) menggambarkan sustainable finance seperti sebuah kubus yang salah satu sisinya merupakan business area, sisi yang lain sustainability. Sisi atas kubus terdiri dari regulation, voluntary standards and ethics, serta governance. Dalam business area terdapat produk, outreach (retail incl. SMEs, microfinance), private banking, investment banking, process and logistic. Sedangkan sisi sustainability terdiri dari social dimension, environmental dimension, economic dimension.

Savu (2012) juga menunjukkan inisiatif yang dilakukan oleh bank-bank di Rumania, yaitu dengan melindungi nasabahnya melalui penggunaan produk dan layanan yang lebih ramah lingkungan, seperti green cards, online banking, electronic bank statements, green motgage, green home equity loans, green commercial buildings loans or green car loans.

Perumusan Hipotesis. Penelitian Sayekti (2006) menguji ukuran komisaris independen, ukuran komite audit, auditor eksternal, dan proporsi blockholders. Hasil pengujian menunjukkan bahwa komisaris independen, ukuran komite audit, dan auditor eksternal terbukti signifikan memengaruhi tingkat pengungkapan CSR dalam laporan tahunan perusahaan.

Penelitian Ayusso, et al. (2007) memeroleh hasil bahwa semakin dewan berperan dalam menangani pertanggungjawaban CSR, maka semakin efektif. Demikian juga dengan ukuran dewan direksi. Sembiring (2005) menyatakan bahwa semakin besar jumlah anggota dewan komisaris, maka akan semakin mudah untuk mengendalikan CEO. Oleh karena itu, jika terdapat kebijakan terkait sustainable finance, dimungkinkan semakin besar anggota dewan komisaris, akan semakin bagus penerapan sustainable finance-nya.

$\mathrm{H} 1=$ Ukuran dewan direksi sebagai salah satu mekanisme governance berpengaruh positif terhadap sustainable finance index.

$\mathrm{H} 2=$ Ukuran dewan komisaris sebagai salah satu mekanisme governance berpengaruh positif terhadap sustainable finance index.

$\mathrm{H} 3=$ Proporsi komisaris independen sebagai salah satu mekanisme governance berpengaruh positif terhadap sustainable finance index. 
H4= Ukuran dewan direksi, ukuran dewan komisaris, proporsi komisaris independen, ukuran perusahaan dan profitabilitas berpengaruh terhadap sustainable finance index.

\section{METODE}

Sampel yang digunakan dalam penelitian ini adalah perusahaan-perusahaan yang terdaftar di Bursa Efek Indonesia tahun 2014. Sampel awal berjumlah 88 perusahaan (lihat tablel 1) untuk industri jasa keuangan, kemudian karena tidak semua data yang dibutuhkan terpenuhi, maka sampel hanya sebesar 65. Setelah melalui proses pemilahan data dan ditemukan outlier, maka sampel akhir menjadi 46.

Data diperoleh dari Bursa Efek Indonesia berupa annual report dan informasi keuangan lainnya yang dapat ditelusuri dari website BEI, yaitu www.idx.co.id. Dalam operasionalisasi variabel, variabel independen yang digunakan adalah variabel mekanisme governance yang secara eksplisit terdiri dari ukuran dewan direksi, ukuran dewan komisaris, dan proporsi komisaris independen. Sedangkan untuk variabel dependen, yaitu sustainable finance index. Untuk variabel kontrol, digunakan total asset, dan ROA. Berikut ini perincian cara pengukurannya: ukuran dewan direksi diperoleh dari jumlah dewan direksi, ukuran dewan komisaris menggunakan penghitungan jumlah dewan komisaris, Sedangkan proporsi komisaris independen dihitung dari proporsi komisaris independen dibagi jumlah dewan komisaris. Variabel dependen sustainable finance index menggunakan content analysis berdasarkan item yang disyaratkan dalam pedoman oleh Internasional Financial Corporation (IFC). Penghitungan indeks mengikuti Haniffa and Cooke (2005) dengan rumus:

$$
\text { SFI }=\frac{\sum X \mathrm{Xij}}{\mathrm{nj}}
$$

Keterangan: $\mathrm{SFI}=$ Sustainable finance index; $\mathrm{nj}=\mathrm{jumlah}$ item untuk perusahaan $\mathrm{j}, \mathrm{nj}=32$;

$\mathrm{Xij}=1$ jika unsur diungkapkan; 0 jika unsur tidak diungkapkan

Model dalam penelitian ini sebagai berikut:

$$
\mathrm{SFI}=\beta 0+\beta 1 \mathrm{DIR}+\beta 2 \mathrm{COM}+\beta 3 \mathrm{INCOM}+\beta 4 \mathrm{SIZE}+\beta 5 \mathrm{ROA}+\varepsilon
$$

Di mana: SFI = Sustainable Finance Index; DIR = ukuran dewan direksi; COM = ukuran dewan komisaris; INCOM = proporsi komisaris independen; SIZE = ukuran preusan; $\mathrm{ROA}=$ Return on Assets $; \beta 0 \ldots \beta 4=$ koefisien yang diestimasi; $\varepsilon=$ error term analysis yang digunakan

\section{HASIL DAN PEMBAHASAN}

Statistik Deskriptif. Berdasarkan statistik deskriptif (Tabel 2) terlihat bahwa rata-rata nilai sustainable finance index (SFI) sebesar 0,35 dengan standar deviasi sebesar 0,27. Nilai indeks ini dapat berarti juga bahwa pengungkapan sustainable finance di Indonesia masih cukup rendah karena berada di bawah 0,5. Rata-rata ukuran dewan direksi (DIR) sebesar 5,130, hal ini dapat berarti pula bahwa rata-rata industri jasa keuangan yang 
menjadi sampel dalam penelitian ini memiliki dewan direksi sebanyak lima orang. Ukuran dewan komisaris (COM) rata-rata sebesar 4,30, artinya rata-rata perusahaan memiliki 4 orang anggota dewan. Proporsi komisaris independen (INCOM) rata-rata sebesar 93,48 dengan standar deviasi sebesar 50,12. Nilai total asset (ln) variabel SIZE rata-rata sebesar 15,73. Nilai profitabilitas (ROA) rata-rata sebesar 1,93.

Hasil Uji Asumsi Klasik. Dalam penelitian ini telah dilakukan uji asumsi klasik, antara lain uji normalitas data, uji multikolinieritas, dan uji heteroskedastisitas, juga uji autokorelasi. Hasil uji normalitas data menggunakan histogram dan probability plot dan menunjukkan bahwa data terdistribusi normal (membentuk lonceng pada gambar histogram dan sebaran error berada di area garis lurus dalam gambar probability plot. Hasil uji multikolinieritas juga menunjukkan bahwa nilai VIF untuk semua variabel di bawah 10 dan nilai tolerance untuk semua variabel dalam penelitian ini berada di atas $10 \%$. Hal ini berarti bahwa dalam model ini tidak terjadi multikolinieritas. Berdasarkan uji heteroskedastisitas melalui scatterplot diperoleh gambaran titik-titik yang menyebar di area atas dan bawah angka nol. Hasil ini menunjukkan bahwa dalam model tidak terjadi heteroskedastisitas. Uji autokorelasi dilakukan dengan menggunakan uji Durbin Watson $(D W)$ yang menunjukkan hasil bahwa nilai $D W$ sebesar 0,599.

Hasil Pengujian Hipotesis. Berdasarkan hasil output SPSS, dapat disimpulkan bahwa model penelitian (regresi) ini sebagai berikut:

$\mathrm{SFI}=1,259+0,074 \mathrm{DIR}+0,02 \mathrm{COM}-0,01 \mathrm{INCOM}-0,078 \mathrm{SIZE}+0,008 \mathrm{ROA}$ $+\mathrm{e} . . .(1)$

Pengaruh hubungan variabel independen terhadap variabel dependen pada model di atas dapat dijelaskan sebagai berikut:

1. Hasil pengujian H 1 (pengaruh variabel DIR terhadap SFI secara parsial) diperoleh koefisien regresi sebesar 0,074 dengan nilai $t_{\text {statistik }} 1,892<2,014$. Pada taraf signifikansi $a=0,05(5 \%)$ dengan nilai signifikansi $0,066>0,05$ mengandung arti bahwa terdapat pengaruh positif, tetapi tidak signifikan antara DIR terhadap SFI. Akan tetapi, pada taraf signifikansi $\alpha=0,10$ (10\%) dengan nilai signifikansi $0,066<$ 0,1, dapat diartikan bahwa DIR berpengaruh positif dan signifikan terhadap SFI pada taraf signifikansi $10 \%$. Nilai koefisien regresi sebesar 0,074 , mengandung makna bahwa setiap DIR mengalami kenaikan sebesar 1, maka SFI juga akan meningkat sebesar 0,074, begitu juga sebaliknya, setiap DIR mengalami penurunan 1, maka SFI juga akan mengalami penurunan sebesar 0,074. Hal ini dapat dikatakan bahwa semakin besar DIR, SFI akan semakin tinggi, begitu juga sebaliknya. Hasil pengujian signifikan pada taraf $10 \%$ sehingga hipotesis penelitian pertama diterima, dimana terdapat pengaruh positif dan signifikan antara DIR terhadap SFI.

2. Hasil pengujian $\mathrm{H} 2$ (pengaruh variabel COM terhadap SFI) menunjukkan bahwa koefisien regresi sebesar 0,02 dengan nilai $t_{\text {statistik }} 0,059<2,014$ pada taraf signifikansi $\alpha=0,05$ (5\%) dengan nilai signifikansi $0,953>0,05$. Hal ini berarti terdapat pengaruh positif, tetapi tidak signifikan antara COM terhadap SFI. Nilai 0,02 pada koefisien regresi mengandung arti bahwa setiap COM mengalami kenaikan 1, maka SFI akan mengalami kenaikan pula sebesar 0,02 , begitu juga sebaliknya, setiap COM mengalami penurunan 1, maka SFI juga akan mengalami penurunan sebesar 0,02. Hasil penelitian ini tidak mendukung hipotesis penelitian yang kedua. 
3. Hasil pengujian $\mathrm{H} 3$ (pengaruh variabel INCOM terhadap SFI) memeroleh koefisien regresi sebesar $-0,01$ dengan nilai $t_{\text {statistik }} 0,098<2,014$ pada taraf signifikansi $a=0,05$ (5\%) dengan nilai signifikansi 0,286 >0,05. Hal ini berarti bahwa terdapat pengaruh negatif, tetapi tidak signifikan antara INCOM terhadap SFI. Nilai -0,01 pada koefisien regresi dapat diartikan bahwa setiap INCOM mengalami kenaikan 1, maka SFI akan mengalami hal yang sebaliknya, yaitu turun sebesar 0,01 , begitu juga sebaliknya, setiap INCOM mengalami penurunan sebesar 1, maka SFI akan mengalami peningkatan sebesar 0,01 . Hasil penelitian ini tidak mendukung hipotesis penelitian yang ketiga.

4. Hasil pengujian variabel kontrol (pengaruh variabel SIZE terhadap SFI) . Koefisien regresi yang diperoleh sebesar $-0,078$ dengan nilai $t_{\text {statistik }} 02,438>2,014$ pada taraf signifikansi $\alpha=0,05(5 \%)$ dengan nilai signifikansi $0,019<0,05$. Hal ini menunjukkan bahwa terdapat pengaruh negatif dan signifikan antara SIZE terhadap SFI. Nilai -0,078 pada koefisien regresi mengandung makna bahwa jika SIZE mengalami kenaikan sebesar 1, maka SFI justru akan menurun sebesar 0,078, begitu juga sebaliknya, setiap SIZE mengalami penurunan sebesar 1, maka SFI akan mengalami kenaikan sebesar 0,078 .

5. Hasil pengujian variabel kontrol (pengaruh variabel ROA terhadap SFI): Koefisien regresi diperoleh sebesar 0,008 , nilai $t_{\text {statistik }} 1,037<2,014$ pada taraf signifikansi $\alpha=$ $0,05(5 \%)$ dengan nilai signifikansi 0,306 > 0,05 yang berarti bahwa terdapat pengaruh positif, tetapi tidak signifikan antara ROA terhadap SFI. Nilai 0,008 pada koefisien regresi memiliki makna bahwa setiap ROA meningkat 1, maka SFI akan meningkat sebesar 0,008, begitu juga sebaliknya, setiap ROA menurun sebesar 1, maka SFI akan menurun sebesar 0,008 .

6. Pengujian hipotesis secara simultan dapat dilakukan dengan membandingkan antara $F_{\text {statistik dengan }} F_{\text {tabel }}$ atau dengan melihat nilai signifikansinya. Berdasarkan output SPSS, nilai $F_{\text {statistik }}$ adalah 1,536 , sedangkan nilai $F_{\text {tabel }} 2,5787$ sehingga nilai $F_{\text {statistik }}$ $1,536<2,5787$ pada taraf signifikansi $\alpha=0,05(5 \%)$, dengan nilai signifikansi 0,200 $>0,05$. Hal ini menunjukkan bahwa secara simultan tidak terdapat pengaruh signifikan antara DIR, COM, INCOM, SIZE, dan ROA terhadap SFI. Hasil pengujian ini tidak mendukung hipotesis penelitian keempat.

Koefisien determinasi atau model fit dari model penelitian ini adalah sebesar 0,161 atau $16,1 \%$, hal ini dapat diartikan bahwa variable SFI dipengaruhi oleh variable DIR, COM, INCOM, SIZE, dan ROA sebesar $16,1 \%$, sisanya $(83,9 \%)$ dipengaruhi oleh faktor lainnya.

Hasil pengujian hipotesis 1 menunjukkan bahwa ukuran dewan direksi berpengaruh signifikan terhadap pengungkapan sustainable finance pada tingkat $10 \%$. Hal ini perlu dipahami bahwa direksi merupakan penentu kebijakan perusahaan sehingga penentuan segala hal yang berhubungan dengan penerapan sustainable finance, termasuk pelaporannya, direksi merupakan pihak yang cukup berpengaruh. Praktik sustainable finance dalam scope internasional menunjukkan bahwa kebijakan terkait sustainability ditentukan oleh dewan direksi (Qingrong et al., 2013). Hasil penelitian ini sejalan dengan Ayusso, et al. (2007) yang memeroleh hasil bahwa semakin dewan berperan dalam menangani pertanggungjawaban CSR, maka semakin efektif. Melalui hasil ini telah terbukti bahwa upaya dari mekanisme governance dengan ukuran dewan direksi sebagai 
proksinya dapat menjadi pendorong penerapan pengungkapan sustainable finance di Indonesia.

Berdasarkan hasil uji hipotesis di atas, hipotesis 2 dan 3 tidak didukung. Hal ini berarti kemungkinan karena sustainable finance masih dalam tahap awal sehingga belum melibatkan dewan komisaris dalam penerapannya. Temuan ini mendukung hasil penelitian Qingrong et al. (2013) yang memberikan ranking praktik governance di industri perbankan China dalam memimpin penerapan sustainable finance. Ranking pertama, perangkat governance yang menghandel penerapan sustainable finance adalah Chairman yang terdiri dari President, Vice Presidents, Board Secretary, dan Pemimpin lainnya. Grup ini bertanggung jawab dalam merencanakan serta mengambil keputusan yang berkaitan dengan penerapan sustainable finance. Hanya sedikit bank yang hanya melibatkan executive director atau executive board, maupun environmental officer saja.

Hasil pengujian variabel control size terlihat signifikan pada tingkat 5\%. Hasil ini konsisten dengan penelitian Ani (2011) bahwa ukuran perusahaan memiliki pengaruh positif signifikan terhadap pelaporan sosial dan lingkungan. Hasil dalam penelitian ini diperoleh koefisien negatif yang berarti pula semakin besar ukuran perusahaan, pelaporannya semakin sedikit. Hal ini terjadi kemungkinan karena perusahaan besar telah melakukan CSR atau sustainable finance-nya dan melaporkannya secara kontinyu sehingga biaya menjadi lebih sedikit.

Hasil pengujian variabel control profitabilitas menunjukkan bahwa ROA memengaruhi pengungkapan sustainable finance, namun tidak signifikan. Temuan ini berbeda dengan temuan Hill et al. (2007) yang menemukan hubungan positif antara CSR dengan kinerja keuangannya. Perbedaan ini kemungkinan karena dalam kinerja dunia perbankan banyak yang harus dipertimbangkan, berbeda dengan perusahaan jenis lainnya.

\section{PENUTUP}

Simpulan. Berdasarkan analisis sebelumnya, dapat disimpulkan hal-hal sebagai berikut: (1) Tingkat pengungkapan sustainable finance di Indonesia masih rendah rata-rata 0,35. Oleh karena itu, dibutuhkan perhatian OJK agar memberikan saran dan pengarahan terkait standar pengungkapan sustainable finance; (2) Mekanisme governance dengan ukuran dewan direksi sebagai proksinya berpengaruh signifikan terhadap pengungkapan sustainable finance; (3) Size secara signifikan juga berpengaruh terhadap pengungkapan sustainable finance; (4) Meskipun variabel lain yang digunakan dalam penelitian ini (ukuran dewan komisaris, proporsi komisaris independen) tidak menghasilkan bukti berpengaruh signifikan, namun variabel tersebut dimungkinakan dapat digunakan dalam penelitian berikutnya. Hasil yang diperoleh ini kemungkinan karena banyak perusahaan yang belum memiliki komitmen untuk menerapkan sustainable finance karena masih merupakan isu baru.

Implikasi. Implikasi dalam penelitian ini adalah: (1) Penelitian ini memberikan gambaran pengungkapan sustainable finance di Indonesia serta gambaran penggunaan standar jika IFC diterapkan di Indonesia agar penetapan standar pengungkapan yang sesuai segera dapat dilakukan oleh pihak OJK; (2) Dengan melihat gambaran pengungkapan sustainable finance, perusahaan dapat lebih memahami isu baru tersebut dan segera menerapkannya; (3) Bagi akademisi, karena masih minimnya penelitian di 
bidang ini, kajian ini dapat menjadi pembuka cakrawala dan bahan referensi sehingga memperkaya khazanah keilmuan.

Keterbatasan. Penelitian ini memiliki keterbatasam sebagai berikut: (1) Menggunakan range pengamatan hanya satu tahun. Dalam penelitian ini, hal ini dilakukan mengingat roadmap sustainable finance dari OJK baru diluncurkan akhir 2014; (2) Pengamatan tidak mempertimbangkan pada masing-masing sub jenis jasa keuangan, seharusnya perlu dilakukan klasifikasi, misalnya industri perbankan, industri asuransi, dan industri pembiayaaan; (3) Sampel yang digunakan masih minim sehingga untuk penelitian selanjutnya perlu menambah sampel yang lebih banyak.

\section{DAFTAR RUJUKAN}

Ani, Salis Musta. (2011) 'The Impact of Good Corporate Governance on The Corporate Social Responsibility Disclosure". Twenty-Third Asian Pacific Conference on International Accounting Issues, Beijing China. Program and Proceedings.

Ayusso, Silvia, Miguel Angel Rodriguez, dan Miguel Angel Arino. (2007) "Maximizing Stakeholders' Interests: An Empirical Analysis of the Stakeholder Approach to Corporate Governance". <http:www.blackwell-synergy.com/doi/abs/10.1111/j.14678683.2006.00495.x> diakses tanggal 5 March 2007.

Daniri, M. A. (2005) Good Corporate Governance: Konsep dan Penerapannya dalam Konteks Indonesia. Jakarta: Gloria Printing.

Gerster, Richard. (2011) Sustainable Finance: Achievements, Challenges, Outlook. Zwitzerland: Gerster Consulting.

Hadad, Muliaman D. dan Istiana Maftuchah. (2015) Sustainable Financing Industri Jasa Keuangan dalam Pembiayaan Berkelanjutan. Jakarta: PT Elex Media Komputindo Kompas Gramedia.

Haniffa, R. M. dan T. E. Cook. (2005) "The Impact of Cultural and Governance on Corporate Social Reporting". Journal of Accounting and Public Policy 24.

Hill, R.P., T. Ainscough, T. Shank, and D.Manullang. (2007) "Corporate Social Responsibility and Socially Responsible Investing: A Global Perspective". J ournal of Business Ethics, 70 (2).

Komite Nasional Kebijakan Governance (KNKG). (2006) Pedoman Umum Good Corporate Governance Indonesia.

Otoritas Jasa Keuangan. (2014) Roadmap Keuangan Berkelanjutan di Indonesia 20152019. Jakarta: Otoritas Jasa Keuangan.

Oyegunle, Adeboye dan Olaf Weber. (2015) Development of Sustainability and Green Banking Regulations: Existing Codes and Practices. No. 65 Tahun 2015. Canada: The Centre for International Governance Innovation (CIGI).

Ozcelik, Funda dan Burcu Avci Ozturk. (2014) "Evaluation of Banks' Sustainability Performance in Turkey with Grey Relational Analysis". The Journal of Accounting and Finance. Juli 2014.

Qingrong, Wang, Lilian Wang, Sun Yiting, dan Guo Lina. (2013) The Sustainable Performance of Chinese Banking and International Financial Institutions Comparative Study. Laporan penelitian hasil kolaborasi China Banking Regulatory Commission (CBRC), WWF, and PWC. 
Savu, Iona Florentina. (2012) "It's Time for Green Banking Management in Romania". Economica, 8 (2), Acta Universitatis Danubius.

Sayekti, Yosefa. (2006) "Corporate Governance (CG) sebagai Faktor Determinan Pengungkapan Informasi Corporate Social Responsibility (CSR) dalam Annual Report Perusahaan.” Paper Program Pascasarjana Ilmu Akuntansi Fakultas Ekonomi UI.

Sembiring, Eddy Rismanda. (2005) "Karakteristik Perusahaan dan Pengungkapan Tanggung Jawab Sosial: Study Empiris pada Perusahaan yang Tercatat di Bursa Efek Jakarta". Seminar Nasional Akuntansi VIII on $15^{\text {th }}-16^{\text {th }}$ September 2005.

Syahroza, Akhmad. (2005) Corporate Governance: Sejarah dan Perkembangan, Teori, Model, dan Sistem Governance serta Aplikasinya pada Perusahaan BUMN. Pidato Pengukuhan Guru Besar Tetap Fakultas Ekonomi Universitas Indonesia. Jakarta: Penerbit Fakultas Ekonomi Universitas Indonesia. 


\section{Lampiran-lampiran}

Lampiran I -- Hasil Pengujian Uji Asumsi Klasik

Normalitas Data

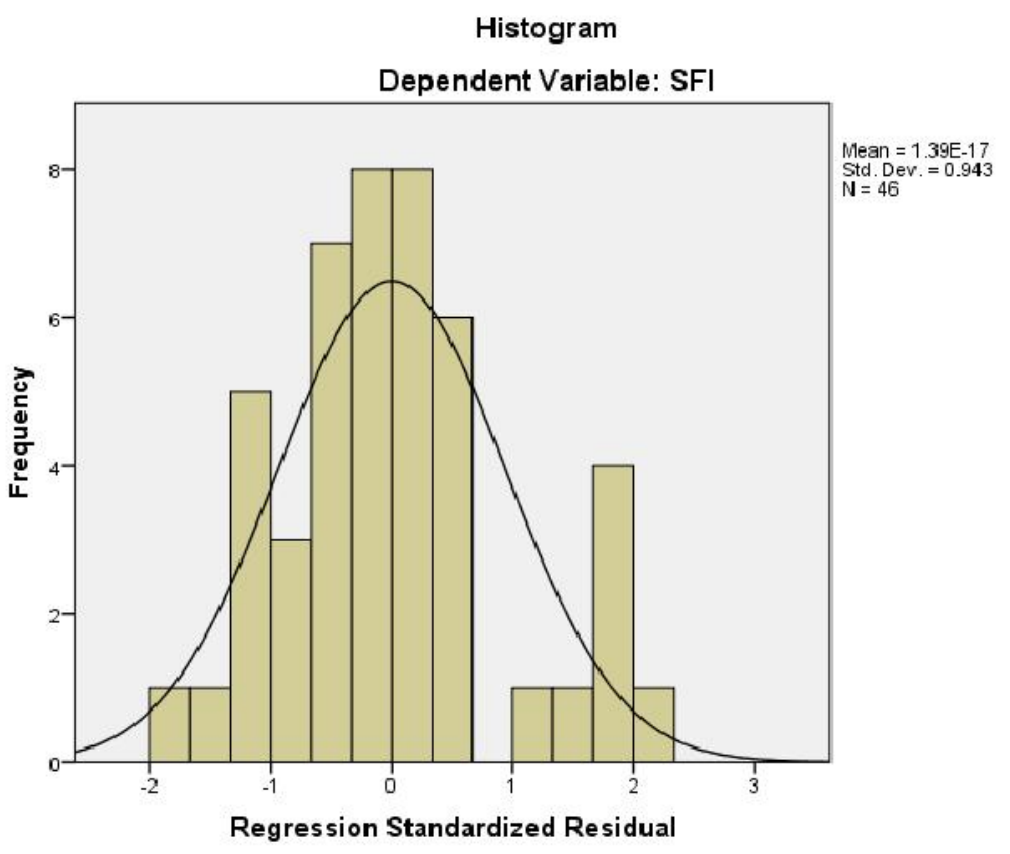

Normal P.P Plot of Regression Standardized Residual

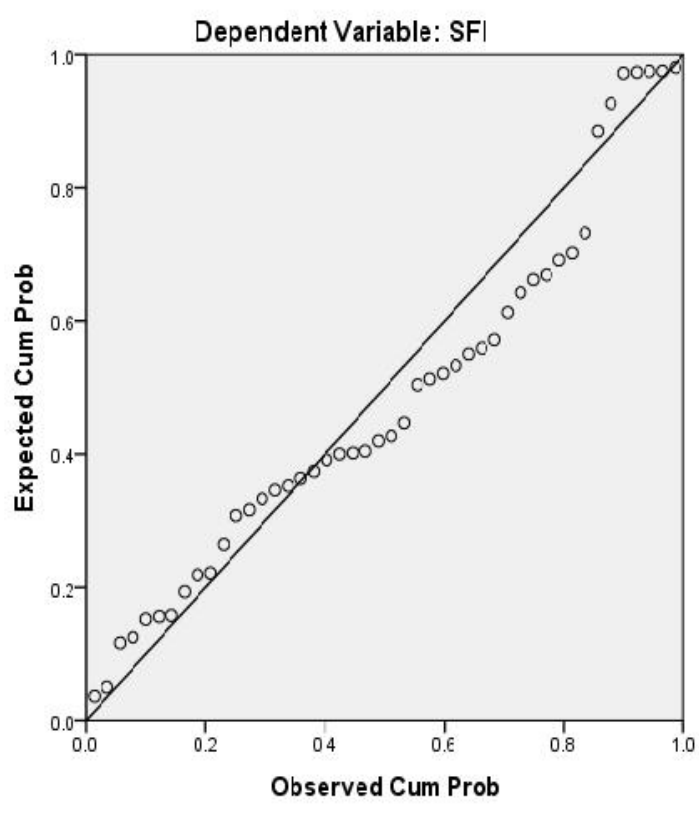


Lampiran II -- Hasil Pengujian Uji Asumsi Klasik

Multikolinieritas

\begin{tabular}{|c|c|c|c|}
\hline Variabel & Tolerance & VIF & Keterangan \\
\hline DIR & 0,131 & 7.635 & Tidak terdapat multikolinieritas \\
\hline COM & 0,287 & 3.490 & Tidak terdapat multikolinieritas \\
\hline INCOME & 0,805 & 1.242 & Tidak terdapat multikolinieritas \\
\hline SIZE & 0,227 & 4.406 & Tidak terdapat multikolinieritas \\
\hline ROA & 0,955 & 1.047 & Tidak terdapat multikolinieritas \\
\hline
\end{tabular}

Lampiran II -- Hasil Pengujian Uji Asumsi Klasik

Heteroskedastisitas 
Scatterplot

Dependent Variable: SFI

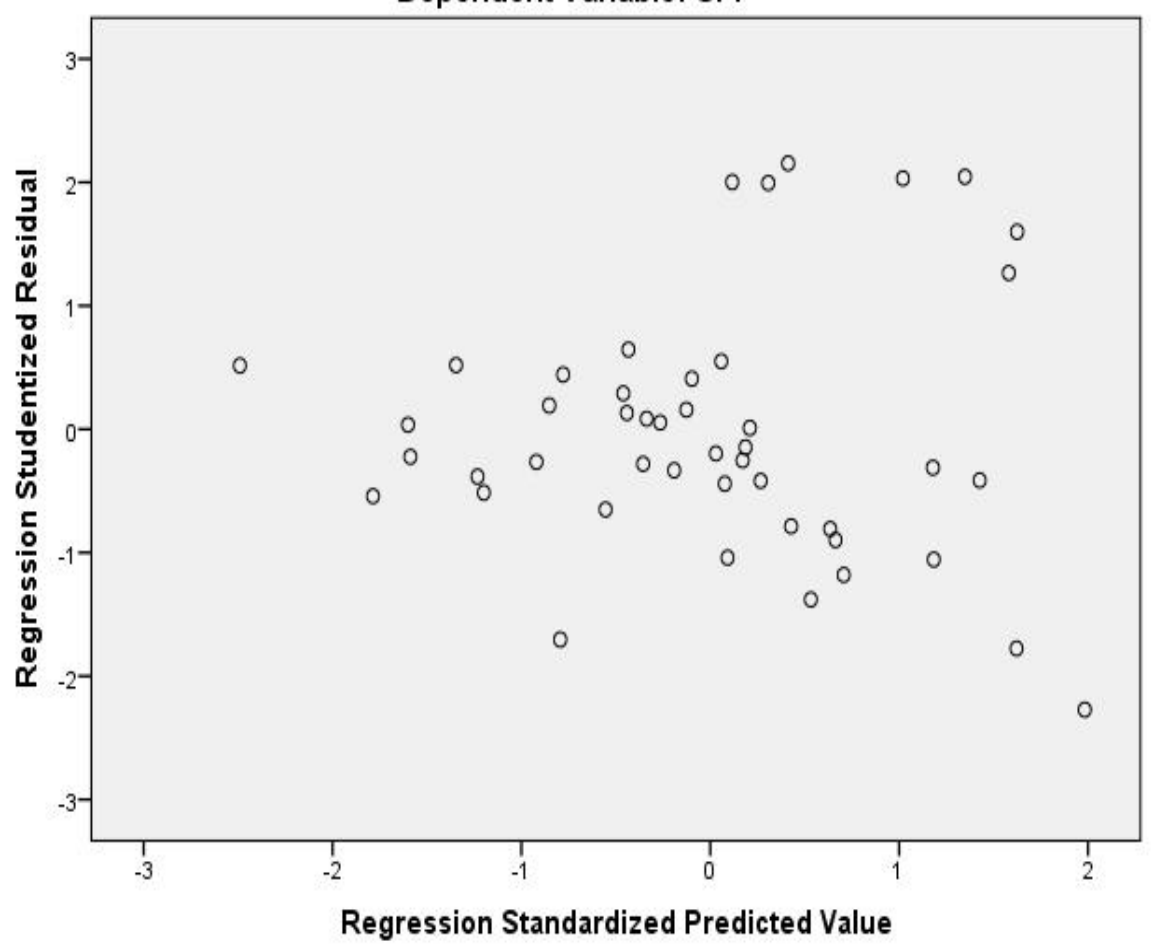

Lampiran III -- Hasil Pengujian Hipotesis

\begin{tabular}{|c|c|c|c|c|c|c|}
\hline \multicolumn{7}{|c|}{ Analisis Partial } \\
\hline $\begin{array}{c}\text { Variabel } \\
\text { Bebas }\end{array}$ & Konstanta & $\begin{array}{c}\text { Koefisien } \\
\text { Regresi }\end{array}$ & $\begin{array}{c}\text { Nilai } \\
\mathrm{t}_{\text {statistik }}\end{array}$ & $\begin{array}{c}\text { Korelasi } \\
\mathrm{r}\end{array}$ & Sig & Keterangan \\
\hline $\begin{array}{l}\text { DIR } \\
\text { COM } \\
\text { INCOM } \\
\text { SIZE } \\
\text { ROA }\end{array}$ & 1,259 & $\begin{array}{c}0,074 \\
0.02 \\
-0,01 \\
-0,078 \\
0,008\end{array}$ & $\begin{array}{c}1,892 \\
0,059 \\
-1.080 \\
-2.438 \\
1.037\end{array}$ & $\begin{array}{c}0,039 \\
0,069 \\
-0,098 \\
-0,125 \\
0,137\end{array}$ & $\begin{array}{c}0,066 * \\
0,953 \\
0,286 \\
0,019 * * \\
0,306\end{array}$ & $\begin{array}{c}\text { Signifikan } \\
\text { Tidak Signifikan } \\
\text { Tidak Signifikan } \\
\text { Signifikan } \\
\text { Tidak Signifikan }\end{array}$ \\
\hline \multicolumn{3}{|c|}{ Analisis Regresi Berganda } & $\begin{array}{c}\mathrm{R} \\
\mathrm{R}^{2} \\
\mathrm{~F}_{\text {statistik }}=\end{array}$ & $\begin{array}{r}0,401 \\
0,161 \\
1,536 \\
\end{array}$ & $\begin{array}{c}\mathrm{T}_{\text {tabel }} \\
\mathrm{F}_{\text {tabel }} \\
\mathrm{Sig} / \mathrm{p}\end{array}$ & $\begin{array}{l}2,0141 \\
2,5787 \\
0,200 \\
\end{array}$ \\
\hline
\end{tabular}

Ket: ** Signifikan pada level 5\%, * Signifikan pada level 10\%

Sumber: Data diolah dari lampiran 
Ani dan Fredy: Mekanisme Governance dan Pengungkapan Sustainable Finance:...

\begin{tabular}{|c|c|c|c|c|c|c|c|c|c|c|c|}
\hline \multicolumn{12}{|c|}{ Coefficients ${ }^{a}$} \\
\hline \multirow[b]{2}{*}{ Mode } & & \multicolumn{2}{|c|}{$\begin{array}{c}\text { Unstandardized } \\
\text { Coefficients }\end{array}$} & \multirow{2}{*}{$\begin{array}{c}\text { Standardized } \\
\text { Coefficients } \\
\text { Beta }\end{array}$} & \multirow[b]{2}{*}{$t$} & \multirow[b]{2}{*}{ Sig. } & \multicolumn{3}{|c|}{ Correlations } & \multicolumn{2}{|c|}{$\begin{array}{c}\text { Collinearity } \\
\text { Statistics }\end{array}$} \\
\hline & & $\mathrm{B}$ & Error & & & & order & Partial & Part & Tolerance & VIF \\
\hline \multirow[t]{6}{*}{1} & $\begin{array}{l}\text { (Cons } \\
\operatorname{tant})\end{array}$ & 1.259 & .389 & & 3.236 & .002 & & & & & \\
\hline & DIR & .074 & .039 & .757 & 1.892 & .066 & .039 & .287 & .274 & .131 & 7.635 \\
\hline & COM & .002 & .035 & .016 & .059 & .953 & .069 & .009 & .009 & .287 & 3.490 \\
\hline & $\begin{array}{l}\text { INCO } \\
\text { M }\end{array}$ & -.001 & .001 & -.174 & $\begin{array}{r}- \\
1.080\end{array}$ & .286 & -.098 & -.168 & -.156 & .805 & 1.242 \\
\hline & SIZE & -.078 & .032 & -.741 & $\begin{array}{r}- \\
2.438 \\
\end{array}$ & .019 & -.125 & -.360 & -.353 & .227 & 4.406 \\
\hline & ROA & .008 & .008 & .154 & 1.037 & .306 & .137 & .162 & .150 & .955 & 1.047 \\
\hline
\end{tabular}

a. Dependent Variable: SFI 